\title{
O GRABEN QUATERNÁRIO DO BAIXO VALE DO RIBEIRÃO COTOVELO: NOTAS PRELIMINARES
}

\author{
Mário Teixeira Rodrigues Bragança ${ }^{(a)}$ \\ (a) Programa de Pós-Graduação em Geografia Física. FFLCH/USP. Professor de Geografia, Prefeitura Municipal \\ de Betim/MG, mario.teixeira@mail.com
}

EIXO: SISTEMAS GEOMORFOLÓGICOS: ESTRUTURA, DINÂMICAS E PROCESSOS

\begin{abstract}
Resumo
O baixo vale do Ribeirão Cotovelo é descrito como uma bacia de sedimentação Quaternária, controlada por falhas normais ativas. Esse processo de sedimentação foi intensificado durante o Pleistoceno e o Holoceno, o que é demonstrado pelo acentuada incisão recente dos canais de drenagem, hipótese confirmada pela datação de alúvios pelo método de luminescência oticamente estimulada. Dados estruturais indicam que as falhas ativas possuem direções predominantes SWNE e SSW-NNE. A morfologia resultante dessa atividade é um graben orientado na mesma direção das falhas e com caimento para sudeste, o que é demonstrado pela migração do leito do Ribeirão Cotovelo neste rumo, abandonando para trás diversos meandros, convertidos em oxbow lakes.
\end{abstract}

Palavras chave: Tectônica Quaternária, graben do Ribeirão Cotovelo, meandos abandonados

\section{Introdução}

Pretende-se avialar a influência de uma tectônica pleistocênica e holocênica na configuração da rede de drenagem e no padrão de sedimentação no setor de jusante da bacia hidrográfica do Ribeirão. $\mathrm{O}$ Ribeirão Cotovelo é afluente da margem esquerda do Rio Paracatu e drena uma área de $795 \mathrm{~km}^{2}$, inseridos no município de Brasilândia de Minas/MG. O curso e seus tributários fluem predominantemente sobre rochas metamórficas Neoproterozóicas do Sub-Grupo Paraopeba, embora a maior parte de suas nascentes esteja situadas em patamares mais elevados, onde ocorrem rochas permocarboníferas do Grupo Santa Fé (Serra do Riacho do Campo) e rochas cretáceas dos Grupos Urucuia e Areado (Serra do Boqueirão) (CAMPOS e DARDENNE, 1997). Toda a bacia está inserida no domínio geomorfológico da Depressão Sanfranciscana (CETEC, 1981).

A bacia possui três domínios geomorfológicos distintos. A montante, o setor ocidental apresenta drenagem dendrítica encaixada nas rochas metamórficas do Sub-Grupo Paraopeba; em alguns locais esse padrão muda a paralelo, devido à adequação de lineamentos estruturais Pré-Cambrianso (HASUI e HARALYI, 1991) aos padrões de dobramentos das rochas. A alta energia do sistema impede a formação de depósitos aluviais de grande extensão e as planícies de inundação possuem formas estreitas e alongadas na direção meridiana, compatível com os lineamentos principais da área.

Também a montante, configura-se um segundo domínio geomorfológico sobre a Serra do Riacho do Campo, no qual a drenagem mantém o padrão dendrítico, porém, fluindo sobre um patamar de relevo 


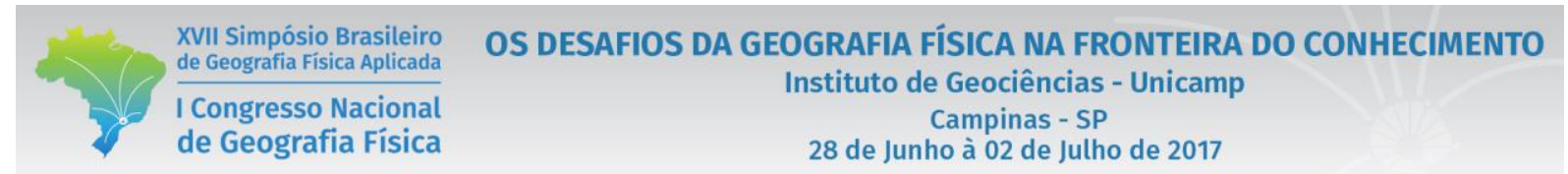

elevado e regular, com baixo grau de entalhamento. Neste setor, ocorre a transição entre as rochas do Sub-Grupo Paraopeba e as do Grupo Santa Fé (CAMPOS e DARDENNE, 1997). A morfologia configura uma borda elevada de planalto com caimento suave para oeste, até alcançar a escarpa da serra. O compartimento separa, neste trecho as drenagens do Ribeirão Santa Fé (a leste) e do Rio Paracatu (a oeste e ao sul).

Finalmente, o baixo vale do Ribeirão Cotovelo, área de estudo, é caracterizado por relevo de rampas de colúvio e terraços, cuja regularidade se estende até o sopé da Serra do Boqueirão (a oeste) e às baixas colinas dos interflúvios que separam a bacia dos afluentes de menor ordem do Rio Paracatu, a leste. A morfologia deste setor é caracterizada por uma ampla planície de inundação, na qual o curso passa de sinuoso a meandrante, com a presença de vales abandonados e diversos oxbow lakes. A área de estudo abrange o baixo vale do Ribeirão Cotovelo e possui cerca de $250 \mathrm{~km}^{2}$ (figura 1).

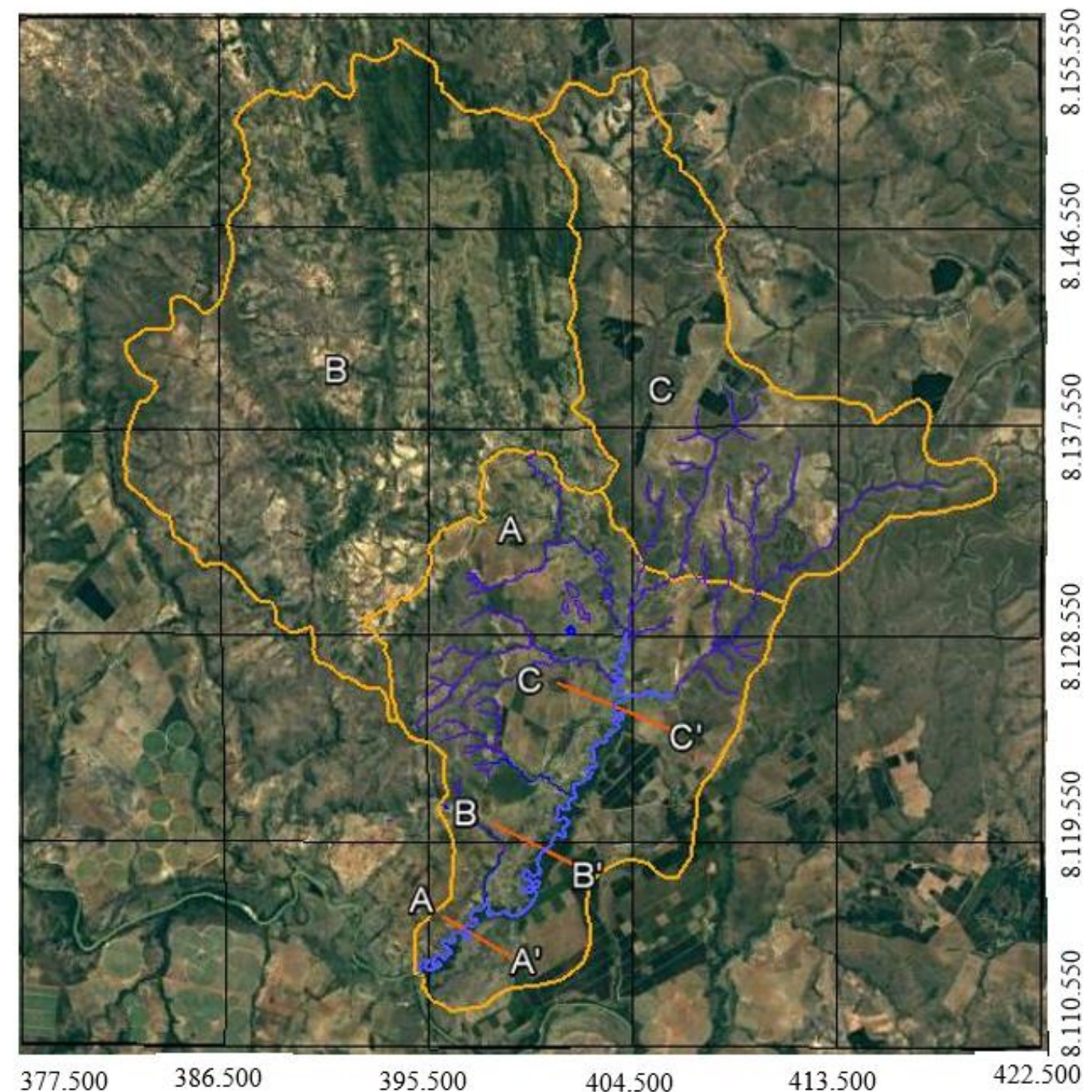

Figura 1: Domínios geomórficos da bacia hidográfica do Ribeirão Cotovelo. A: Domínio de jusante (área de estudo). B: Domínio de montante ocidental. C: Domínio de montante oriental. Localização dos perfis topográficos da área de estudo. A-A' (jusante), B-B' (intermediário), C-C' (montante). 
XVII Simpósio Brasileiro

de Geografia Física Aplicada

I Congresso Nacional

de Geografia Física

\section{OS DESAFIOS DA GEOGRAFIA FÍSICA NA FRONTEIRA DO CONHECIMENTO \\ Instituto de Geociências - Unicamp \\ Campinas - SP \\ 28 de Junho à 02 de Julho de 2017}

\section{Metodologia}

A investigação seguiu a proposta metodológica de Ab’Sáber (1969), a partir da qual iniciou-se a compartimentação e descrição topográfica do relevo, o que foi feito mediante a análise das cartografia topográfica disponivel na escala 1:100.000 (folhas Serra do Boqueirão e Santa Fé de Minas). Em razão da pequena extensão da área de estudos, esse procedimento foi refinado sobre imagens de satélite da banda 8 do sensor Thematic Mapper (Landsat 7), modo pancromático com resolução espacial de 10 metros e sobre imagens de alta resolução espacial (Google Earth). A imgem Landsat-7 foi obtida gratuitamente no site do INPE (http://www.dsr.inpe.br). As imagens Google Earth estão disponíveis para consulta online através o aplicativo Google Earth ${ }^{\text {tu }}$.

$\mathrm{Na}$ etapa seguinte, passou-se à descrição das estruturas superficiais da paisagem, através da observação da geologia e dos solos, o que se alcançou mediante estudo e descrição de taludes e afloramentos rochosos. Durante este processo foram observados, registrados e descritos dados estruturais e evidências de atividade tectônica recente. Duas amostragens de alúvios para datação por luminescência oticamente estimulada (LOE) (RHODES, 2011) foram feitas em terraços associados aos canais abandonados; uma coleta no terraço do Ribeirão Cotovelo e outra no terraço do Córrego das Trombas, seu tributário da margem direita.

A explicação da dinâmica paisagem seguiu a interpretação dos dados de campo com base nos conceitos da morfotectônica (SAADI, 1991). Foram produzidos perfis topográficos transversais ao vale do Ribeirão Cotovelo, os quais mostram a inclinação da bacia de noroeste para sudeste, a sequência de meandros abandonados e a morfologia indicativa de bordas delimitadas por falhas.

\section{Resultados e discussão}

A configuração da rede de drenagem sugere uma acentuada migração do canal do Ribeirão Cotovelo de noroeste para sudeste. Essa migração se deve ao basculamento da bacia na mesma direção, obedecendo a movimentação de um sistemas de falhas normais orientado SW-NE. Há um amplo leque aluvial orientado na mesma direção e posicionado junto à foz dos Córregos do Morcego, Riachinho e das Trombas, tributários da margem direita do Ribeirão Cotovelo, que nascem na vertente leste da Serra do Boqueirão. O morfologia resulta da interdigitação das três áreas de dejeção. O leque avança sobre a planícies de inundação e o curso do Ribeirão Cotovelo se desloca para sudeste, paralelamente ao avanço da frente de sedimentação, deixando para trás um grande número de meandros abandonados, os quais se converteram em oxbow lakes.

Perfis topográficos do baixo vale, próximo à foz do Ribeirão Cotovelo (figura 2), do setor intermediário da bacia de sedimentação (figura 3) e do setor de montante (figura 4) dão uma ideia da organização morfológica do vale. Sobre esses perfis foram plotadas falhas de direção SW-NE, observadas em campo. 


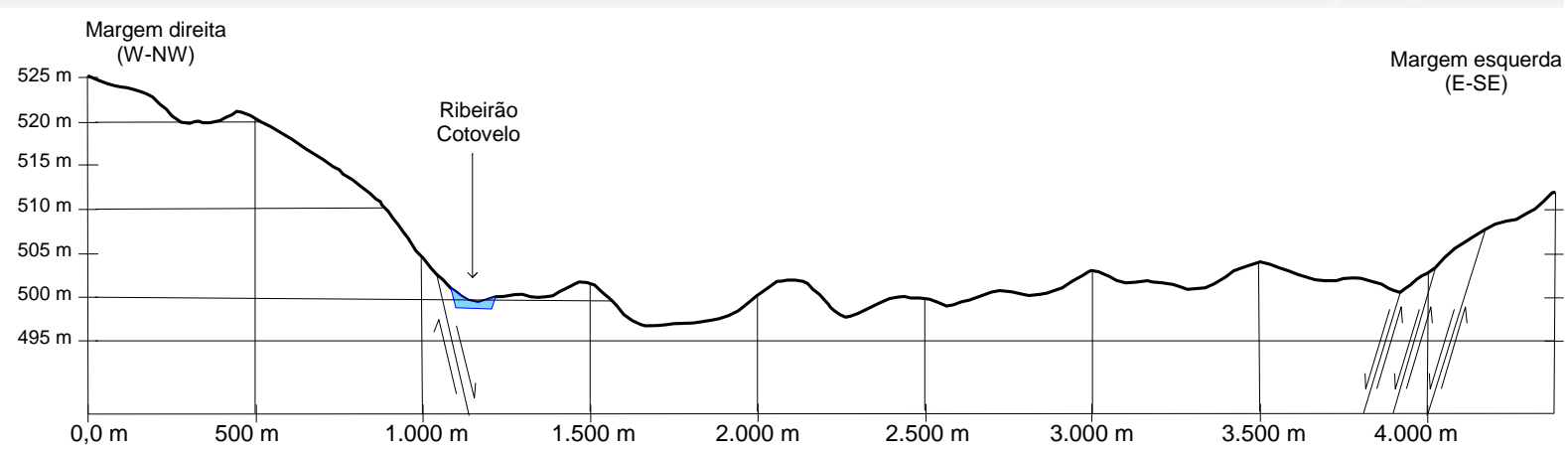

Figura 2: Perfil A-A’: Perfil topográfico do setor de jusante da depressão do Ribeirão Cotovelo.

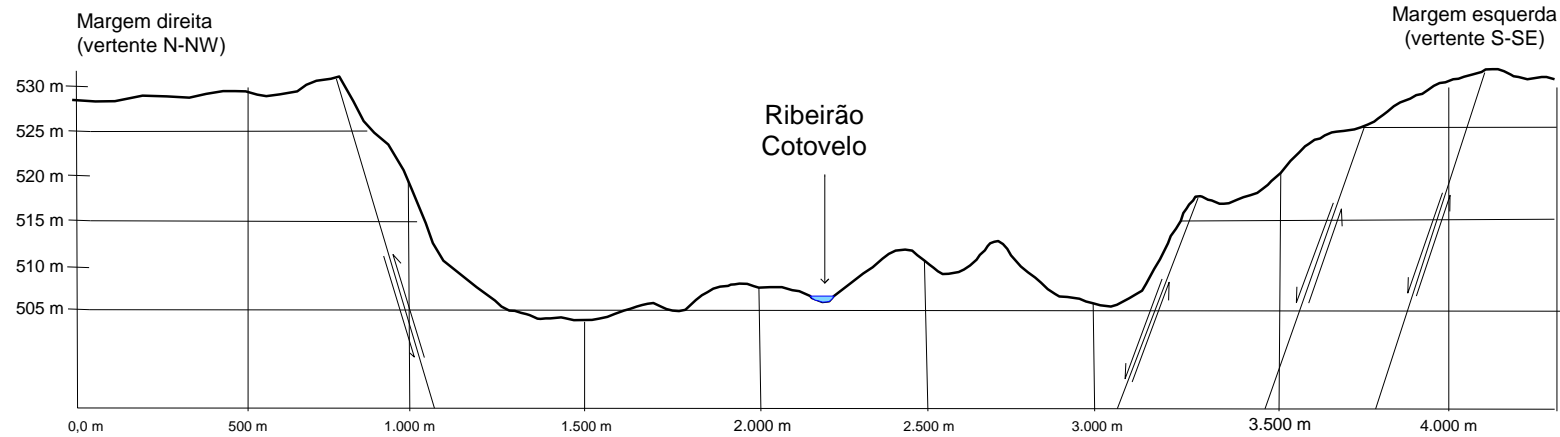

Figura 3: Perfil B-B’: Perfil topográfico do setor intermediário da depressão do Ribeirão Cotovelo.

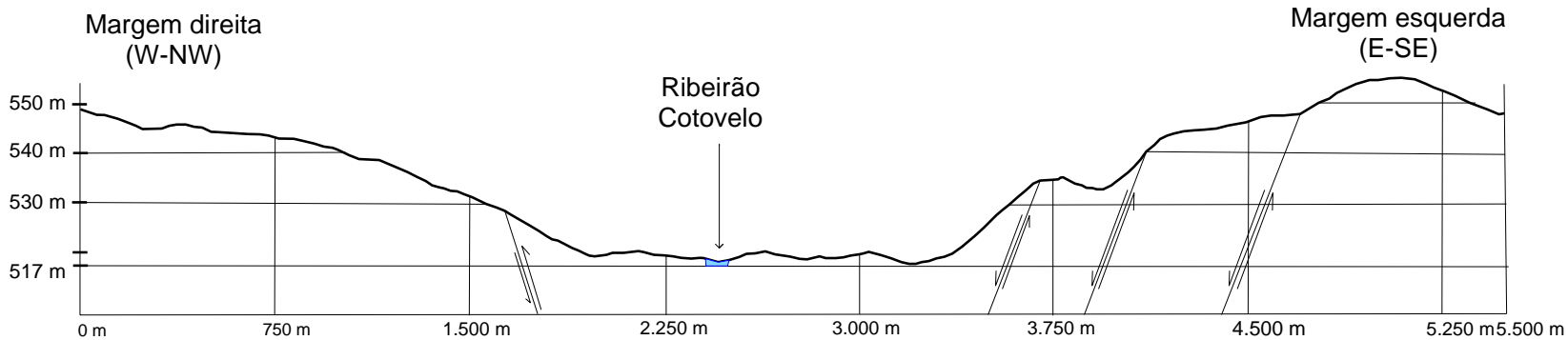

Figura 4: Perfil C-C': Perfil topográfico da parte do setor de montante da depressão do Ribeirão Cotovelo

Os dados estruturais (figura 5) confirmam a existência de quatro direções predominantes nos lineamentos crustais: NW-SE, NNW-SSE, SW-NE, SSW-NNE. As duas primeiras, datadas do PréCambriano e associadas ao contato Faixa Brasília - Cráton do São Francisco (HASUI e HARALYI, 1991). As duas direções posteriores, datadas do Terciário (CAMPOS e DARDENNE, 1997).

As duas direções direções posteriores, SW-NE e SSW-NNE, são datadas do Terciário e associam-se a fenômenos de reativação que resultaram na instalação do graben do baixo vale do Ribeirão Cotovelo, sobre qual se processa a sedimentação Terciária e Quaternária. Esse fenômeno teve início, provavelmente a partir do Pleistoceno, devido à deriva da Placa Sulamericana para oeste (HASUI, 1990), ao contínuo processo de abertura do Oceano Atlântico (ALMEIDA et al., 1996), aos movimentos reflexos da Tectônica Andina (FRUTOS, 1988) e, também, à acomodação dos blocos crustais que compõem da bacia antepaís do cráton do São Francisco. Essa cronologia encontra 
respaldo na datação de alúvios de terraços da bacia do Córrego das Trombas e o Ribeirão Cotovelo, os quais apresentaram idades de $26.250( \pm 4.100)$ anos e $28.550(( \pm 4.880)$ anos, respectivamente. Nos locais amostrados os terraços apresentam altura média de 8 metros, o que resulta numa taxa estimada de dissecação do relevo da ordem de 28 a 30 centímetros a cada 1.000 anos.

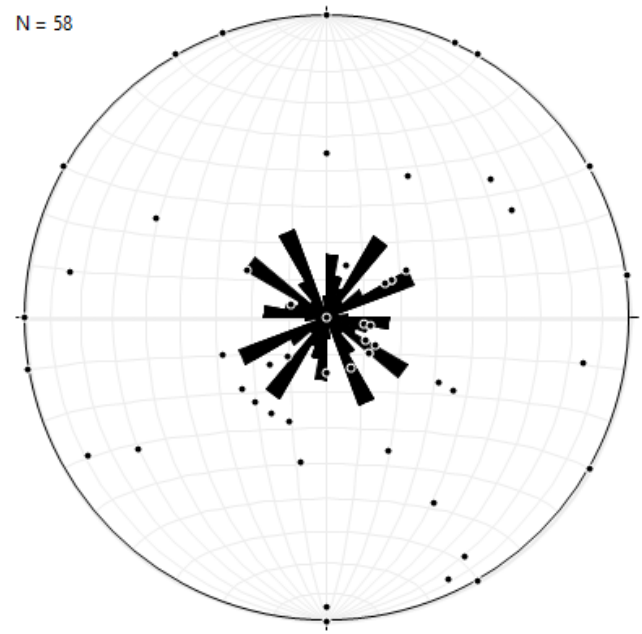

Figura 5: Diagrama de roseta das direções de falhas observadas no baixo vale do Riberião Cotovelo.

\section{Bibliografia}

AB'SABER, A.N. Um conceito de geomorfologia a serviço das pesquisas sobre o Quaternário. In: Geomorfologia, n. 18, Instituto de Geografia, Universidade de São Paulo, 1969. 23p.

ALMEIDA, F.F.M.; CARNEIRO, C.D.R.; MIZUSAKI, A.M.P. Correlação do magmatismo das bacias da margem continental brasileira com o das áreas emersas adjacentes. São Paulo. Revista Brasileira de Geociências, v. 26, n.3, p. 125-138, 1996.

CAMPOS, J.E.G.; DARDENNE, M.A. Origem e evolução tectônica da Bacia Sanfranciscana. São Paulo. Revista Brasileira de Geociências, v. 27, n. 3, p. 283-294, 1997.

CETEC. FUNDAÇÃO CENTRO TECNOLÓGICO DE MINAS GERAIS. $\mathbf{2}^{\mathbf{0}}$ Plano de Desenvolvimento Integrado do Noroeste Mineiro: Recursos Naturais. Belo Horizonte, 1981. 2v. (Série de Publicações Técnicas, 2); Contém 16 mapas.

FRUTOS, J. Evolución de las trayectorias de esfuerzo en la tectónica de los Andes Meridionales. In: Congresso Geológico Chileno, 5, 1988, Santiago, Anais... Santiago, Universidad de Chile, Tomo I, p. 261-281, 1988.

HASUI, Y. Neotectônica e aspectos fundamentais da tectônica ressurgente no Brasil. Workshop sobre Neotectônica e Sedimentação Continental Cenozóica no Sudeste do Brasil. Belo Horizonte. Boletim da Sociedade Brasileira de Geologia. Núcleo Minas Gerais, n. 11, junho, 1990. p. 1-31.

HASUI, Y.; HARALYI, N.L.E. Aspectos lito-estruturais e geofísicos do Soerguimento do Alto Paranaíba. São Paulo. Geociências, v. 10, p. 57-77, 1991.

RHODES, E.J. Optically stimulated luminescence dating of sediments over the past 200.000 years. Annual Review of Earth and Planetary Science, v. 29, p. 461-488, 2011.

SAADI, A. Ensaio sobre a Morfotectônica de Minas Gerais. 1991, 285f. Tese (Professor Titular). Instituto de Geociências, Universidade Federal de Minas Gerais. Belo Horizonte, 1991. 